\title{
Entre a psicanálise e a degenerescência: sexualidade e doença mental no início do século XX no Brasil
}

\author{
C ristiana Facchinetti \\ Ana Teresa A. Venancio
}

O texto de Henrique Roxo, publicado em 1919 e aqui apresentado, fundamenta-se em grande medida na psicanálise, discutindo o papel central da sexualidade nos casos de doença mental, em especial da demência precoce. Nosso artigo analisa as relações entre a psicanálise e a psiquiatria para demonstrar o modo sui generis como esses campos de saber foram combinados na construção do mental como objeto científico em nosso contexto.

Palavras-chave: Psicanálise, psiquiatria, história, Brasil 
De fato, em artigo inaugural dos Anais do Instituto de Psiquiatria, Roxo destacaria que no novo Instituto

Os assuntos escolhidos serão preferentemente aqueles que possam esclarecer pontos obscuros da psiquiatria, concorrer para que se disponha de um tratamento mais eficiente das psicopatias, comprovar as alterações bioquímicas que nestas existam, solucionar problemas obscuros da química biológica, demonstrar quais alterações anátomo ou histopatológicas existentes nas doenças mentais. (Roxo, 1942, p. 9)

Já nas primeiras décadas do século XX possível testemunhar o investimento de Roxo na divulgação da ciência psiquiátrica, ${ }^{3}$ tendo ele publicado artigos na maior parte dos periódicos médicos e psiquiátricos brasileiros. ${ }^{4}$ Seus artigos e livros, bem como sua influência sobre as práticas psiquiátricas no Brasil das décadas de 1930 e 1940, ressaltavam uma psiquiatria de base organicista, com ênfase na relação entre doenças mentais e lesões ou disfunções cerebrais (Bueno, 1988, p. 129).

Assim, todas as partes do corpo, com ênfase no crânio e na cavidade bucal deveriam ser examinadas na observação de um paciente. dever-se-ia examinar a existência de deformidades cranianas, verificar estrabismo, anotar defeitos em dentes e orelhas, examinar a existência de deformações ósseas, feminismo, membro viril grande ou pequeno em excesso, cegueira, gaguez ou surdo-mudez, entre outros, na busca de estigmas físicos e psíquicos que sinalizavam a degeneração (Roxo, 1907).

É possível entrever de suas recomendações que a psiquiatria biológica por ele preconizada não incluía apenas lesões, mas estava marcada também por determinações raciais, ainda que associadas a fatores sociais. Logo, o dr. Henrique entendia que haveria doenças mentais advindas do desenvolvimento do cérebro, por sua vez distinto em cada raça. Roxo afirmava então que o cérebro dos negros era menos evoluído do que o dos brancos e por isso mais propenso a certos tipos de loucura. Vale dizer, a inferioridade dos negros não seria devida à sua constituição física ou à cor, mas ao fato de que a evolução não havia ainda se estabelecido neles como teria acontecido aos brancos (Roxo, 1904, p. 182).

3. Beça (1981) aponta que nos anos de 1920 e 1930, Henrique Roxo manteve-se em segundo lugar em número de publicações na área de psiquiatria.

4. São dele, por exemplo, os seguintes artigos: "Causas de reinternação de alienados no Hospício Nacional”, 1908; "Estudo clínico da confusão mental (Psychoses Infecciosas e Psychoses Autotóxicas)", 1918; "Perturbações nervosas e mentaes que se observam nas doenças do útero e dos ovários”, 1928. 
Somando a noção de características hereditárias a fatores sociais como a escravatura, Roxo retomava a proposta higiênica convocada pela Intelligentsia nacional, propondo que o controle dessa população de loucos e degenerados de toda sorte deveria ser feito através da promoção da saúde e educação, que poderia transformá-los.

Nesse cenário, as normas da higiene passaram a regular o campo das trocas sexuais, estabelecendo nele as fronteiras entre o normal e o patológico. De acordo com os postulados de Magnan e Morel, e também de Krafft-Ebing, a sexualidade se definiria pela finalidade - a reprodução biológica. As satisfações eróticas sem objetivo, isto é, não voltadas para a conservação da espécie, eram perversas e indicavam degeneração, hereditariedade doentia e a involução dos seres. ${ }^{5}$ Sob esse ponto de vista teórico, o instinto sexual não se manifestaria apenas no ato sexual, mas também no plano moral, sendo responsável pela produção de características psíquicas e padrões de comportamento que poderiam ser transmitidos aos descendentes (Birman, 1978).

O controle da população pela higiene mental tinha como um dos seus objetivos, portanto, extirpar o caráter excessivo, desregrado e degenerado da raça brasileira para que pudéssemos adentrar em um novo patamar - moderno e, por conseguinte, saudável (Facchinetti, 2001). Os psiquiatras passavam a ser os cogestores dessa promessa de futuro, propondo organizar casamentos e procriações. Sem políticas do Estado e a participação dos médicos e educadores, nada restaria ao negro senão tornar-se o locus da maior ameaça social: constituir-se como fator de degenerescência do brasileiro (Roxo, 1904, p. 182).

Assim, não é de se estranhar que a psiquiatria de Roxo, aparentemente contradizendo a perspectiva teórica organicista, tenha passado a incluir uma vertente psicogênica que atribuía à psicanálise importante papel no trabalho de descoberta da gênese de problemas da sexualidade nos distúrbios mentais. A psiquiatria, auxiliada pela psicanálise, participava do projeto de pedagogia moral e higiene mental do povo (Nunes, 1988, p. 71). Por conseguinte, vemos cruzar o discurso psicanalítico com regras e preceitos morais para exames nupciais, educação de crianças e prevenção contra o $\operatorname{crime}^{6}$ (Facchinetti, 2001, p. 88). Nesse recorte específico, a psicanálise era apenas um dos elementos para o diagnóstico, passando a se encaixar no trinômio do orgânico, da moral e da vida moderna.

Em uma carta a Oskar Pfister, Freud (1926) havia explicitado seu desejo de que a psicanálise fosse realizada de forma leiga, sendo poupada do vínculo com a medicina e as religiões. Sabemos, entretanto, que ela acabou por se ver

5. Sobre o assunto, vide também Lanteri-Laura, Georges. Leituras das perversões.

6. Vide, por exemplo, Porto-Carrero, J. P. O caráter do escolar segundo a psicanálise. 
muitas vezes mergulhada em grandes disputas que envolveram psiquiatras e religiosos. Diante disto, não é demais lembrarmos que, como em outros contextos nacionais, a doutrina criada por Freud já nos anos 1910 e 1920, se difundia no Brasil através de duas vias principais: de um lado, havia uma difusão "leiga", entre intelectuais e artistas. De outro, a psicanálise era discutida e divulgada por renomados psiquiatras e higienistas mentais em seus trabalhos clínicos e conferências (Facchinetti e Ponte, 2003).

Além de Henrique Roxo, entre os catedráticos de psiquiatria ou especialistas interessados pela psicanálise estavam Juliano Moreira, Franco da Rocha, Durval Marcondes, Porto-Carrero, Arthur Ramos, Maurício de Medeiros e Ulisses Pernambuco (cf. Russo e Carrara, 2002). Mas apesar da precoce divulgação da psicanálise no meio psiquiátrico do país - há indícios de que Juliano Moreira tenha proferido aulas sobre o método da interpretação dos sonhos ainda em sua cátedra na Bahia, em 1899 (apud Perestrello, 1987, p. 23) - as iniciativas de divulgação dos temas freudianos pela psiquiatria brasileira permaneceram isoladas por longo tempo.

O artigo “Sexualidade e demência precoce”, de $1919^{7}$ que ora comentamos, faz parte desse esforço de divulgação da psicanálise e, mais especialmente, do uso de terapêuticas modernas e científicas no tratamento de alienados.

Publicado nos Archivos Brasileiros de Neuriatria e Psiquiatria, o artigo nos fornece um quadro bastante interessante do recorte do saber psicanalítico, tal como era utilizado por alguns dos maiores representantes da elite médica do período como uma contribuição para o organicismo psiquiátrico:

Em psiquiatria moderna, o exame psicoscópico representa elemento de grande valia para uma diagnose exata. Cada vez mais se presta a ele maior atenção, pois conhecendo-se bem aquilo em que o indivíduo medita, meio caminho terse-á andado para um tratamento conveniente. (Roxo, 1919, p. 337)

Para Roxo, Freud tinha o mérito de ter chamado atenção para a importância do distúrbio do pensamento na gênese da doença mental (Roxo, 1919, p. 338; 1934, p. 127-8). Sua terapêutica era considerada valiosa por facilitar ao médico conseguir saber o que ia no pensamento do paciente, uma vez que o conhecimento acerca de seus pensamentos patológicos permitiria moldar-lhe o espírito. Conseqüentemente, o método psicanalítico da psicoscopia possibilitaria, segundo Roxo, "fazer vir à tona o complexo recalcado" e demonstrar ao doente que ele devia deixá-lo de lado (Roxo, 1934, p. 133). Vale dizer, o médico propunha sua

7. Este artigo foi o resultado de um trabalho de Roxo apresentado no II Congresso Brasileiro de Neurologia, Psiquiatria e Medicina Legal (apud Engel, 1998/1999). 


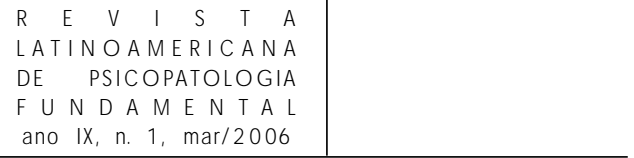

troca por atividades sublimadas (Ponte, 1999, p. 56), em especial a administração de um trabalho ou atividade complexos que desviassem a atenção do doente dos conteúdos psíquicos angustiantes.

Para tornar eficaz a investigação “psicanalítica” do pensamento, Henrique Roxo propunha como estratégia captar a confiança do doente para que ele se expandisse. O pensamento expresso através dessa fala livre deveria ser então avaliado atentando-se para a emoção manifestada diante das perguntas, sua preferência ou aversão a certos temas, para seus olhares investigadores e momentos de distração (Roxo, 1919, p. 340). Como método para atingir seus objetivos, Freud oferecia a interpretação dos sonhos, que apresentava para o autor o problema de colocar o médico em situação de dependência do examinado (ibid., p. 337), e o método da associação livre. O último era preferido por Roxo, na medida em que permitiria ao médico superar as barreiras de defesa do analisado e pegá-lo de surpresa:

Coloca-se o doente num sofá e o médico à cabeceira deste vai conversando com ele, dando-lhe corda como vulgarmente se diz. O doente vai respondendo sem emoção a várias perguntas que se lhe façam, até que num dado momento a sua fisionomia se transforma, a voz se altera e ele busca rapidamente mudar de assunto. É que se realizou o método catártico, que faz vir à tona os complexos recalcados, e se atingiu o ponto vital de Moeder, que é aquele em que há a máxima emoção e se localiza, conseqüentemente, o complexo recalcado. (Roxo, 1934, p. 130, apud Ponte, 1999, p. 57-8)

Além da metodologia freudiana, à qual Roxo incluía ainda a análise de atos falhos (Roxo, 1919, p. 344), o autor achava que poderia ser útil incluir na pesquisa a análise dos reflexos psicoelétricos de Lippmannn, galvânicos ou o aparelho do problema vital de Maeder (ibid., p. 333).

Ainda que considerasse exagerada a afirmação freudiana de que a sexualidade estaria no cerne de todas as neuroses, Roxo reconhecia que um distúrbio mental poderia ser causado por "preocupação de natureza sexual” (ibid., p. 338, 340). De fato, uma vida sexual “acidentada” (ibid., p. 338), com impotências psíquicas, desregramentos, desestabilidades e dificuldades no matrimônio, poderiam produzir distúrbios neuróticos marcados por mau humor, irritabilidade, inibição, sentimento de humilhação e angústia. Ainda segundo o autor, a luta constante da consciência para abafar os acidentes da vida sexual e a determinação voluntária de seguir os ditames sociais provocavam um mal-estar que acabava por descortinar, sob a forma de sintomas, aquilo que se quereria esconder de si e dos outros.

A argumentação de Roxo sobre os processos psicogênicos advindos da vida sexual que levavam à doença mental, era combinada também a uma visão organicista. A centralidade da vida psíquica não aparece, nesse texto, vinculada 
aos argumentos freudianos mais específicos sobre a filogênese da sexualidade, sua importância advindo mais do fato de que o "homem é sempre escravo da matéria” (ibid., p. 338), de uma matéria orgânica, de uma natureza, donde se inclui a natureza sexual.

É dessa combinação de paradigmas que podemos entender o desenvolvimento do texto em torno especificamente do papel da sexualidade nos casos de demência precoce. Partindo da demonstração da importância da vida sexual e de suas influências na vida social dos indivíduos, Roxo dá destaque ao papel da sexualidade na conformação desse quadro nosológico específico, um dos mais importantes de fins do século XIX, cunhado por Emil Kraëpelin e inserido dentro de um quadro de referências clínicas que encontrava sua síntese no Compêndio de Psiquiatria, publicado pelo psiquiatra alemão.

Em seu tratado psiquiátrico - que alcançara oito edições atualizadas e ampliadas de 1883 a 1919 - as categorias nosológicas eram forjadas a partir do estabelecimento de correlações estáticas entre os sintomas e as lesões das patologias psiquiátricas, a exemplo da medicina anatomoclínica do século XIX. Para tanto, Kraëpelin definira como principais critérios diagnósticos o "curso" e o "estado" da doença, combinando-os de modo particular.

Nesse contexto, a categoria de demência precoce vinha designar um curso, uma evolução muito peculiar (no sentido de desenvolvimento) que dava um adjetivo distintivo a uma manifestação mórbida específica: precoce à demência. Tratava-se de um quadro patológico em que o aparecimento da demência se dava geralmente fora do período biológico a ela correspondente - a velhice, não sendo nunca identificada com a chamada demência senil e podendo aparecer apenas até os quarenta anos de idade.

Devido a sua fase terminal deficiente, sua etiologia ancorava-se na suspeita da existência de lesões cerebrais, mesmo que ainda não comprovadas; enquanto suas formas de aparecimento (confusional e alucinatória) levavam à hipótese da presença de um fator tóxico, provavelmente autotóxico. A demência precoce era então definida como um estado em que a inteligência, a memória e a orientação se manteriam intactas, enquanto a afetividade, o julgamento, a vontade e, por conseguinte, a "personalidade” seriam afetados profundamente (Bercherie, 1989, p. 173).

Interessante notar que ainda que cite Jung, Roxo não faz referência à categoria de esquizofrenia, já cunhada em 1906 por Eugen Bleuler e que vinha exatamente se contrapor à vertente psiquiátrica kraepeliniana. ${ }^{8}$

8. Segundo Venancio (1999), a aproximação e interlocução de Bleuler com Freud e Jung - este último tendo sido aluno de Bleuler e por ele introduzido às teorias freudianas - teria propiciado essa inflexão no conhecimento psiquiátrico vigente. 
A criação do termo esquizofrenia relacionava-se estreitamente com o surgimento, na psiquiatria, da chamada "corrente psicodinâmica”, emergente na Alemanha na década de 1900, sendo a primeira a dialogar com as idéias de Freud no contexto europeu, alicerçada na importância dada à idéia de inconsciente, que já integrava o cenário “científico" da época. ${ }^{9}$

Como nos indica Bleuler (1911), a criação da categoria esquizofrenia, primeiramente designada no plural (o grupo das esquizofrenias) a fim de enfatizar o pressuposto de que não se podia deduzir de sua sintomatologia e de sua evolução uma única entidade mórbida, vinha exatamente se contrapor à idéia da demência precoce. Sua caracterização estava menos centralizada na questão da evolução do quadro e mais na consideração de que se tratava de uma cisão das funções psíquicas. Essa cisão partiria proeminentemente da afetividade, ocasionando um afrouxamento básico das associações e dificultando a síntese mental diretiva do eu, como atestavam os chamados sintomas fundamentais da esquizofrenia: distúrbios afetivos, perda associativa, autismo e ambivalência.

A obra de Henrique Roxo parece assim congregar diferentes correntes e teorias psiquiátricas que, no contexto europeu, estiveram bem mais dissociadas: de um lado, o uso da categoria demência precoce, cujo mentor filiava-se ao que Shorter (1997) chamou de primeira psiquiatria biológica - como vimos, a importância dada nas análises de H. Roxo à dimensão orgânica dos pacientes testemunha essa filiação. De outro lado, observa-se a defesa explícita ao método psicanalítico e de grande parte do aporte teórico sobre o dinamismo da vida psíquica que o fundamenta. Desse modo, ainda que a demência precoce fosse, para o autor, marcada pela supressão da evolução mental, ela também se favorecia da condição humana de disfarce dos sentimentos e idéias. Por isso Roxo afirma que a idéia de natureza sexual também é predominante no quadro nosológico em questão: uma natureza - como bem explicita o autor - em que tanto a dimensão orgânica, representada pelas glândulas endócrinas e sexuais, quanto o pensamento são expressões da vida sexual (Roxo, 1919, p. 340-1).

Nesse sentido, o método psicanalítico da associação livre parecia-lhe adequado para o tratamento da demência precoce, uma vez que permitia ao médico perseguir o pensamento voltado para a sexualidade e ao qual se vincularia a emoção escondida. O tema da sexualidade traduzia por esta forma a possibilidade

9. O trabalho de Bleuler (1911) sobre a esquizofrenia - mesmo considerando-se a primeira aparição dessa categoria em 1906 - é posterior à constituição da psicanálise, enquanto teoria fundada por Freud na noção de inconsciente. A noção de inconsciente já estava presente no capítulo VII de A interpretação dos sonhos (1900) e em 1906 Freud tinha publicado também “Estudos sobre a histeria” (1893/5), "Psicopatologia da vida cotidiana” (1901) e "Três ensaios sobre a teoria da sexualidade” (1905). 
de lidar tanto com a dimensão orgânica quanto com a dimensão psíquica. Nesse quadro de referências, a doença mental como objeto científico psiquiátrico era reinscrita, ao mesmo tempo, como física e moral.

\section{Referências}

BEçA, Eugênia Turenko. Reformulação da assistência psiquiátrica: realidade e perspectiva. Neurobiologia, v. 44, n. 3, p. 223-48, 1981.

Bercherie, Paul. Os fundamentos da clínica: história e estrutura do saber psiquiátrico. Rio de Janeiro: Jorge Zahar, 1989.

BIRman, Joel. A psiquiatria como discurso da moralidade. Rio de Janeiro: Graal, 1978. Bleuler, Eugen. Dementia Praecox or The Group of Schizophrenias. New York: International Universities Press, 1911.

BuEno, João Romildo. O aspecto da psiquiatria biológica: uma revisão histórica. Jornal Brasileiro de Psiquiatria, Rio de Janeiro, v. 37, n. 3, p. 127-32, 1988.

EnGel, Magali Gouveia. As fronteiras da anormalidade: psiquiatria e controle social. História, Ciências, Saúde - Manguinhos [online], Rio de Janeiro, v. 5, n. 3, p. 547-63, nov/1998-fev/1999. Acesso em 24/1/2006.

Facchinetti, Cristiana. Deglutindo Freud: sobre a digestão do discurso psicanalítico no Brasil. 2001. 217 p. Tese (doutorado em Teoria Psicanalítica). Universidade Federal do Rio de Janeiro.

O pathos como marca identitária: representações de brasileiro e suas conseqüências na estilização das subjetividades. III Congresso Brasileiro de Ciências Sociais e Humanas em Saúde, UFSC, Florianópolis, SC, julho de 2005.

Facchinetti, Cristiana e Ponte, Carlos. De barulhos e silêncios: contribuições para a história da psicanálise no Brasil. Psyché, Campinas, v. I, ano VII, p. 59-83, 2003.

Freud, Sigmund (1893/5). Estudos sobre a histeria. In: Edição Standard Brasileira das Obras Psicológicas Completas. Rio de Janeiro: Imago, 1990. v. II.

(1900). A interpretação dos sonhos. In: Edição Standard Brasileira das Obras Psicológicas Completas. Rio de Janeiro: Imago, 1990. v. IV e V.

(1901). Psicopatologia da vida cotidiana. In: Edição Standard Brasileira das Obras Psicológicas Completas. Rio de Janeiro: Imago, 1990. v. VI.

(1905). Três ensaios sobre a teoria da sexualidade. In: Edição Standard Brasileira das Obras Psicológicas Completas. Rio de Janeiro: Imago, 1990. v. VII.

(1926). A questão da análise leiga. In: Edição Standard Brasileira das Obras Psicológicas Completas. Rio de Janeiro: Imago, 1990. v. XX. 
KraëPelin, Emil. Psychiatrie. Ein Lehrbuch für Studierende und Ärzte. Achte, vollständig umgearbeitete Auflage. I u. II. Band. Allgemeine Psychiatrie. Leipzig: Barth Verlag, 1909 (vgl. 1910a, 1913a, 1915a; unveränderter Nachdruck 1920).

LANTERI-LAURA, Georges. Leituras das perversões. Rio de Janeiro: Zahar, 1994.

Moreira, Juliano. Classificação em Medicina Mental. Archivos Brasileiros de Neuriatria e Psychiatria, Rio de Janeiro, ano I, p. 93-115, $1^{\circ}$ trimestre 1919.

Nunes, Silvia Alexim. Da Medicina Social à Psicanálise. In: Birman, Joel (org.). Percursos na história da psicanálise. Rio de Janeiro: Taurus, 1988.

- Perestrello, Marialzira (org.). História da Sociedade Brasileira de Psicanálise do Rio de Janeiro: suas origens e fundação. Rio de Janeiro: Imago, 1987.

Ponte, Carlos Fidelis da. Médicos, psicanalistas e loucos: uma contribuição à história da psicanálise no Brasil. 1999. Dissertação (Mestrado em Saúde Pública). Fundação Oswaldo Cruz, Escola Nacional de Saúde Pública. [on-line]. Acesso em 24/1/2006. Porto-Carrero, Júlio P. O caráter do escolar segundo a psicanálise. Revista de Psicanálise, São Paulo, v. 1, n. 1, p. 63-69, 1929.

Roxo, Henrique. Perturbações mentais nos negros no Brasil. Brazil Médico, Rio de Janeiro, n. 18, p. 182, maio/1904.

Dos estados mentaes nas grandes nevroses. Archivos Brasileiros de Psychiatria, Neurologia e Sciencias Affins, Rio de Janeiro, ano III, p. 247-63, 1907.

Causas de reinternação de alienados no Hospício Nacional. Archivos Brasileiros de Psychiatria, Neurologia e Medicina Legal, Rio de Janeiro, ano VI, n. 1 e 2, p. 403-15, 1908.

Estudo clínico da confusão mental (Psychoses Infecciosas e Psychoses Autotóxicas). Annaes da Faculdade de Medicina do Rio de Janeiro, Rio de Janeiro, ano II, p. 83-104, 1918.

Sexualidade e Demência Precoce. Archivos Brasileiros de Neuriatria e Psychiatria, Rio de Janeiro, ano I, p. 337-49, $1^{\circ}$ trimestre 1919.

Perturbações nervosas e mentaes que se observam nas doenças do útero e dos ovários. Tribuna Médica, ano XXXII, 1928.

Psicanálise. In: Psicanálise e outros estudos. Rio de Janeiro: Conxson, 1933.

Psico-analise. Arquivos de Medicina Legal e Identificação. Rio de Janeiro: Imprensa Nacional, 1934.

Instituto de Psiquiatria. Anais do Instituto de Psiquiatria, Rio de Janeiro, n.1, p. 3-11, 1942.

Russo, Jane Araújo e CARrara, Sérgio Luís. A psicanálise e a sexologia no Rio de Janeiro de entreguerras: entre a ciência e a auto-ajuda. História, Ciências, Saúde - Manguinhos [online], Rio de Janeiro, v .9, n. 2, p. 273-90, maio-ago/2002. Acesso em: 26/1/ 2006.

Russo, Jane Araújo. A difusão da psicanálise no Brasil na primeira metade do século $\mathrm{XX}$ - da vanguarda modernista à rádio-novela. Estudos e Pesquisas em Psicologia, 
Rio de Janeiro, ano 2, n. 1, p. 53-64, 2002.

SHORTER, Edward. The first biological psychiatry. In: A History of Psychiatry. New York: John Wiley \& sons, 1997.

Venancio, Ana Teresa A. O “eu dividido” moderno e a constituição do saber psiquiátrico. Psicologia Clínica, Rio de Janeiro, v. 11, p. 77-106, 1999.

Ciência psiquiátrica e política assistencial: a criação do Instituto de Psiquiatria da Universidade do Brasil. História, Ciência e Saúde - Manguinhos, Rio de Janeiro, v. 10, n. 3, p. 883-900, set-dez/2003.

Venancio, Ana Tereza A. e Carvalhal, Lázara. A classificação psiquiátrica de 1910: ciência e civilização para a sociedade brasileira. In: JACó-VILlela et al. (orgs.). Cliopsyché ontem: fazeres e dizeres psi na história do Brasil. Rio de Janeiro: RelumeDumará/Faperj, 2001, p. 151-7.

\section{Resumos}

El texto de Henrique Roxo, publicado en 1919 y aqui presentado, se fundamenta sobretodo en la teoría psicoanalítica, discutiendo el papel central de la sexualidad en los casos de enfermedad mental, muy especialmente de la demencia precoz. Nuestro artículo analiza las relaciones entre el psicoanálisis y la psiquiatría, para demostrar la manera sui generis en que esos campos fueron combinados en la construcción del mental como objeto científico, en Brasil.

Palabras clave: Psicoanálisis, psiquiatría, historia, Brasil

Le texte de Henrique Roxo, publié en 1919 et présenté ici, s'appuye surtout sur la théorie psychanalytique, en discutant le rôle central de la sexualité dans les cas de maladie mentale, surtout de la démence précoce. Notre article analyse les relations établis entre la psychanalyse et la psychiatrie, pour montrer le moyen sui generis de la construction du mental comme objet scientifique au Brésil.

Mots clés: Psychanalyse, psychiatrie, histoire, Brésil

The text by Henrique Roxo published in 1919 and presented here is based essentially on psychoanalytic theory, and discusses the core role of sexuality in cases of mental illness, particularly dementia praecox. Our article analyzes the relations established between psychoanalysis and psychiatry to indicate the unique method of constructing the mental as a scientific object in Brazil.

Key words: Psychoanalysis, psychiatry, history, Brazil

Versão inicial recebida em setembro de 2005

Aprovado para publicação em dezembro de 2005 